\title{
Questionnaire Survey about Liver Disease and Lifestyle for Audience of the Regional Seminar
}

\author{
Kanae Kimura-Sasaki ${ }^{1}$, Yuji Kawahigashi ${ }^{1}$, Haruhiko Nobayashi ${ }^{2}$, Michio Sata ${ }^{3,4}$ and Yumiko Nagao ${ }^{1}$ \\ ${ }^{1}$ Department of Organ System Interactions and Information, Faculty of Medicine, Saga University, Japan \\ ${ }^{2}$ Community and Culture Department, Hokuriku Gakuin Junior College, Japan \\ ${ }^{3}$ Nishinihon Hospital, Kumamoto, Japan \\ ${ }^{4}$ Research Center for Innovative Cancer Therapy, Kurume University School of Medicine, Japan
}

Submission: October 16, 2017; Published: October 25, 2017

"Corresponding author: Kanae Kimura-Sasaki, Department of Organ System Interactions and Information, Faculty of Medicine, Saga University, Japan, Tel: +81-952-34-2516; Fax: +81-952-34-2516; Email: sr2094@cc.saga-u.ac.jp

\begin{abstract}
Background: We have held a regional education seminar (Seminars for Digestive Disease) for gastrointestinal disease patients, their families and other general participants for over 10 years. In this study, a survey of seminar participants in 2015 evaluated the relationship of dietary habits and lifestyle to liver disease, and examined the value of the seminar.

Materials and methods: A questionnaire survey was conducted on participants in the 24th Seminars for Digestive Disease about age, sex, height, weight, diet, exercise habits, smoking habits, tooth brushing and dental visits. Univariate and multivariate analyses were performed to evaluate factors affecting the presence or absence of liver disease.

Results: There were 132 participants, 72 of whom had liver disease. Compared to people without liver disease, the odds ratio of participants with liver disease who attended the seminars at least several times was 4.13 times higher $(\mathrm{P}<0.01)$. Among participants with liver disease, the odds ratio was 3.32 times higher $(\mathrm{P}<0.05)$ for those who scarcely skip meals, 4.94 times higher $(\mathrm{P}<0.01)$ for those who spent more than 5,000 yen a month for supplements, and 9.06 times higher $(\mathrm{P}<0.001)$ for those without a coffee drinking habit.
\end{abstract}

Conclusion: By implementing the Seminars for Digestive Disease, patients exhibited behavioral changes that consciously implemented measures useful for improving dietary life and for preventing or treating liver diseases, thus demonstrating the usefulness of the seminars. However, because sufficient enlightenment activities have not penetrated into several items, we suggest the seminars should be continued in the future.

Keywords: Liver disease; Regional education seminar; Questionnaire survey; Lifestyle; Supplement; Coffee

Abbreviations: QOL: Quality of Life; HCC: Hepatocellular Carcinoma; BCAA: Branched Chain Amino Acids; HCV: Hepatitis C Virus; BMI: Body Mass Index; AAA: Aromatic Amino Acids

\section{Introduction}

Diet and nutrition are closely related to gastrointestinal disorders, and it has been confirmed that nutritional status, life expectancy and quality of life (QOL) are particularly related to liver diseases. Therefore, improvement of nutritional status by maintenance of muscle mass or intake of a nighttime meal is regarded as important [1-3].

In our department, we have various processes to disseminate information that will revitalize regional medicine, and to conduct practical activities and research that will improve medical care, especially for patients with hepatocellular carcinoma (HCC) and diseases other than liver diseases caused by hepatitis virus (so- called extrahepatic lesions). We also seek to clarify unknown aspects of these disease conditions by expanding advanced medical care and examination systems. We have been conducting regional education seminars (Seminars for Digestive Disease) for patients with digestive organ diseases, mainly liver diseases, their families, and others in the general population since 2005. We previously reported on the population's awareness of and behaviors towards digestive organ diseases observed through 10 years of Seminars for Digestive Disease $[4,5]$.

In addition, we developed the branched chain amin Seikatsu Bunkasya Co., Inc, Chiba, Japan, marketed science 2007 o acids (BCAA) and zinc-containing supplement, Aminofeel (Seikatsu 
Bunkasya Co., Inc, Chiba, Japan, marketed since2007)[6-11], and established the value of consumption of amazake (a sweet and non-alcoholic Japanese beverage made from fermented rice) before bedtime as nighttime meal therapy for patients with cirrhosis (ingestion of $200 \mathrm{kcal} /$ day for 12 weeks) [12]. Under these conditions, we have been providing nutrition information centered on meals about prevention and treatment of liver diseases and lifestyle, along with a variety of medical information. Furthermore, resident checkups in areas highly infected with hepatitis C virus (HCV) have continued since 1990, and epidemiological studies on food and nutrition items were conducted [13].

Hepatitis $\mathrm{C}$ is an inflammatory disease caused by infection of the liver with $\mathrm{HCV}$, and it is said that 1.9 to 2.3 million persons are infected by HCV in Japan. About 30\% of viruses are naturally excluded by the action of immunity when infected with HCV, but about $70 \%$ of viruses remain in the liver without being eliminated [14]. As a result, hepatocytes are repeatedly destroyed and regenerated, inflammation occurs in the liver and chronic hepatitis $\mathrm{C}$ develops. When inflammation caused by viruses continues for a long time, hepatitis $\mathrm{C}$ gradually produces liver cell destruction and fibrosis, and cirrhosis develops and contributes to HCC. Consequently, it has been reported that the incidence of HCC in HCV-infected individuals is 15 to 20 times higher than that in non-infected individuals [15]. Furthermore, about $65 \%$ of hepatocellular carcinoma, which accounts for the majority of HCC, is caused by HCV infection [16]; therefore, proper treatment of hepatitis $\mathrm{C}$ is important.

Treatment for hepatitis C has greatly advanced in recent years, and it has become possible to heal hepatitis $\mathrm{C}$ patients by removal of HCV with treatment for a minimum of 12 weeks. Oral anti-viral drugs have not only a higher virus control rate than traditional interferon therapy, but also have significantly shorter treatment periods and reduced side effects; as a result, they greatly improve the burden on people infected with HCV.

On the other hand, it is well known that dietary habits and behaviors are related to the development of diseases. Currently, not much research has been done on changes in awareness and behavior from the provision of information regarding liver disease, nor on changes in QOL and a sense of well-being.

This study was designed to analyze the dietary habits and behaviors of participants in the Seminars for Digestive Disease, and the relationships between awareness of lifestyle habits and liver diseases.

\section{Materials and Methods}

\section{Outline of Seminars for Digestive Disease}

The $24^{\text {th }}$ Seminars for Digestive Disease was held as a regional education seminar in Kasuga, Prefecture Fukuoka in Japan on September 26, 2015. The seminor consisted of 4 lectures on themes that focused on treatment, prevention and diet for liver diseases (Part 1), and on questions and answers
(Part 2) between the participants and lecturers.

Lecture 1: To the time when hepatitis $\mathrm{C}$ is cured by internal medicine

Lecture 2: (i) The mind and body of liver disease patients, (ii) How to respond to a questionnaire survey on lifestyle habits

Lecture 3: A liver disease diet that works soon - How to make coffee

Lecture 4: Health of the whole body from the mouth Periodontal disease and liver disease

\section{Questionnaire Survey on Lifestyle}

We distributed paper questionnaire surveys on lifestyle along with lecture materials at the inception of the regional education seminar. In the first part of the lecture, the lecturer explained the purpose and the answer method. Completing the questionnaire was voluntary, and the survey was conducted on an anonymous basis. It was also explained that the responses to the questionnaire and the survey results were not to be used for any other purpose. The questionnaires were collected during Part 1 of the lecture at the venue after being completed. This study was conducted according to the "Helsinki Declaration" and "Ethical guidelines on clinical research".

Survey items on the questionnaire were age, sex, height, weight, history of disease, habit of meal skipping, frequency of meat or fish intake, awareness of ideal dietary habits, ingestion habits, expenses of dietary supplements (supplements), consumption habits (types and amounts of alcoholic beverages and coffee), types and amounts of exercise, smoking habits and amounts, the number of tooth brushings per day, dental visits within one year, and participation in the regional education seminar. In addition, respondents were asked at the end of the questionnaire to describe the reasons for participation in this Seminar for Digestive Disease.

\section{Analysis}

Comparisons of questionnaire items between groups with and without liver disease were implemented. For the comparisons among groups, $\chi 2$-test, t-test or Wilcox on ranksum test was used according to the characteristics of each item. Multiple classification analysis was conducted for the relevance of each item with the presence or absence of liver disease. The statistical significance level was set to $\mathrm{P}<0.05$ in a two-tailed test, and JMP Pro 12.2.0 (SAS Institute Inc.) was used as statistical software.

\section{Results}

There were 146 participants in the $24^{\text {th }}$ Seminars for Digestive Disease. Completed questionnaires on lifestyle habits were collected from 136 (47 males and 89 females) of these participants, for a response rate of $93.2 \%$. Of the responders, 4 females did not answer about the presence or absence of liver disease; therefore, 132 responders who provided an answer were analyzed. 


\section{Advanced Research in Gastroenterology \& Hepatology}

Table 1: Characteristics of the subjects.

\begin{tabular}{|c|c|c|c|c|c|c|c|c|}
\hline & & \multicolumn{2}{|c|}{ Total $(n=132)$} & \multicolumn{2}{|c|}{ Liver Diseases (+) $(n=72)$} & \multicolumn{2}{|c|}{ Liver Diseases (-) $(n=60)$} & P Value \\
\hline \multicolumn{2}{|c|}{ Sex (Males/Females) } & \multicolumn{2}{|c|}{$47 / 85$} & \multicolumn{2}{|c|}{$28 / 44$} & \multicolumn{2}{|c|}{$19 / 41$} & $\mathrm{P}=0.3872$ \\
\hline \multirow{8}{*}{ Age (years) } & 30 's & 5 & $3.7 \%$ & 0 & $0.0 \%$ & 5 & $8.3 \%$ & \multirow{6}{*}{$P<0.0001$} \\
\hline & 40 's & 13 & $9.6 \%$ & 1 & $1.4 \%$ & 12 & $20.0 \%$ & \\
\hline & 50 's & 19 & $14.0 \%$ & 7 & $9.7 \%$ & 12 & $20.0 \%$ & \\
\hline & 60 's & 38 & $27.9 \%$ & 24 & $33.3 \%$ & 14 & $23.3 \%$ & \\
\hline & 70 's & 40 & $29.4 \%$ & 27 & $37.5 \%$ & 13 & $21.7 \%$ & \\
\hline & 80 's & 16 & $11.8 \%$ & 13 & $18.1 \%$ & 3 & $5.0 \%$ & \\
\hline & Unanswered & 1 & $0.7 \%$ & 0 & $0.0 \%$ & 1 & $1.7 \%$ & - \\
\hline & Mean \pm SD & \multicolumn{2}{|c|}{$65.4 \pm 12.2$} & \multicolumn{2}{|c|}{$70.1 \pm 8.7$} & \multicolumn{2}{|c|}{$59.1 \pm 13.2$} & $\mathrm{P}<0.0001$ \\
\hline BMI & Mean \pm SD & \multicolumn{2}{|c|}{$22.4 \pm 3.7$} & \multicolumn{2}{|c|}{$22.3 \pm 3.7$} & \multicolumn{2}{|c|}{$22.7 \pm 3.8$} & $\mathrm{P}=0.4534$ \\
\hline
\end{tabular}

The subject characteristics are shown in Table 1 . Of the 132 subjects, 72 (28 males and 44 females) had liver disease, and the age of those with liver disease was significantly higher

$(\mathrm{P}<0.0001)$ than those without liver disease. There was no difference in body mass index (BMI) due to the presence or absence of liver disease.

Table 2: Comparison of lifestyle by having liver disease or not.

\begin{tabular}{|c|c|c|c|c|c|c|}
\hline & Total $(n=132)$ & \multicolumn{2}{|c|}{ Liver Diseases (+) (n=72) } & \multicolumn{2}{|c|}{ Liver Diseases (-) $(n=60)$} & P Value \\
\hline \multirow{4}{*}{$\begin{array}{c}\text { The } \\
\text { number of } \\
\text { participations } \\
\text { in the } \\
\text { seminar }\end{array}$} & First time & 11 & $15.3 \%$ & 27 & $45.0 \%$ & $P=0.0002$ \\
\hline & 1 4times & 30 & $41.7 \%$ & 14 & $23.3 \%$ & $\mathrm{P}=0.0261$ \\
\hline & 5 9times & 21 & $29.2 \%$ & 9 & $15.0 \%$ & $\mathrm{P}=0.0531$ \\
\hline & $>10$ times & 10 & $13.9 \%$ & 10 & $16.7 \%$ & $\mathrm{P}=0.6576$ \\
\hline \multirow{4}{*}{ Miss a meal } & Rare & 61 & $84.7 \%$ & 43 & $71.7 \%$ & $\mathrm{P}=0.0412$ \\
\hline & Sometimes & 8 & $11.1 \%$ & 15 & $25.0 \%$ & $\mathrm{P}=0.0386$ \\
\hline & Often & 1 & $1.4 \%$ & 1 & $1.7 \%$ & $\mathrm{P}=0.9029$ \\
\hline & Unanswered & 2 & $2.8 \%$ & 1 & $1.7 \%$ & - \\
\hline \multirow{3}{*}{ Supplement } & Take & 36 & $50.0 \%$ & 20 & $33.3 \%$ & $\mathrm{P}=0.0452$ \\
\hline & Not take & 35 & $48.6 \%$ & 40 & $66.7 \%$ & $\mathrm{P}=0.0452$ \\
\hline & Unanswered & 1 & $1.4 \%$ & 0 & $0.0 \%$ & - \\
\hline \multirow{4}{*}{$\begin{array}{l}\text { Payment for } \\
\text { supplement } \\
\text { (/month) }\end{array}$} & 0yen & 35 & $48.6 \%$ & 40 & $66.7 \%$ & $\mathrm{P}=0.0452$ \\
\hline & 1 4999yen & 8 & $11.1 \%$ & 11 & $18.3 \%$ & $\mathrm{P}=0.2290$ \\
\hline & $\geqq 5000$ yen & 27 & $37.5 \%$ & 6 & $10.0 \%$ & $\mathrm{P}=0.0003$ \\
\hline & Unanswered & 2 & $2.8 \%$ & 3 & $5.0 \%$ & - \\
\hline \multirow{5}{*}{$\begin{array}{l}\text { Habitual } \\
\text { drinking of } \\
\text { alcohol }\end{array}$} & Not drink & 37 & $51.4 \%$ & 18 & $30.0 \%$ & $\mathrm{P}=0.0160$ \\
\hline & $\begin{array}{c}\text { Sometimes } \\
\leqq 1 \text { time } / 2 \sim 3 \mathrm{wks})\end{array}$ & 19 & $26.4 \%$ & 24 & $40.0 \%$ & $\mathrm{P}=0.0831$ \\
\hline & Often(1 4times/wk) & 9 & $12.5 \%$ & 10 & $16.7 \%$ & $\mathrm{P}=0.4718$ \\
\hline & Mostly everyday & 7 & $9.7 \%$ & 7 & $11.7 \%$ & $P=0.6930$ \\
\hline & Unanswered & 0 & $0.0 \%$ & 1 & $1.7 \%$ & - \\
\hline \multirow{5}{*}{$\begin{array}{l}\text { Habitual } \\
\text { drinking of } \\
\text { coffee }\end{array}$} & Drip coffee & 25 & $34.7 \%$ & 26 & $43.3 \%$ & $\mathrm{P}=0.2751$ \\
\hline & Instant coffee & 19 & $26.4 \%$ & 27 & $45.0 \%$ & $\mathrm{P}=0.0208$ \\
\hline & Almost not drink & 25 & $34.7 \%$ & 5 & $8.3 \%$ & $\mathrm{P}=0.0004$ \\
\hline & Other & 3 & $4.2 \%$ & 1 & $1.7 \%$ & - \\
\hline & Unanswered & 0 & $0.0 \%$ & 1 & $1.7 \%$ & - \\
\hline \multirow{3}{*}{$\begin{array}{l}\text { Dental visit } \\
\text { within one } \\
\text { year }\end{array}$} & Not done & 12 & $16.7 \%$ & 19 & $31.7 \%$ & $P=0.0429$ \\
\hline & Done & 59 & $81.9 \%$ & 41 & $68.3 \%$ & $\mathrm{P}=0.0692$ \\
\hline & Unknown & 1 & $1.4 \%$ & 0 & $0.0 \%$ & - \\
\hline
\end{tabular}


Significant differences in lifestyle due to the presence or absence of liver disease are shown in Table 2. The rate of subjects who answered "almost never skip meal" was significantly higher in subjects with liver disease $(\mathrm{P}<0.05)$ compared with those without liver disease. In contrast, the rate of subjects who answered "skips meal from time to time" was significantly higher in those without liver disease $(\mathrm{P}<0.05)$.

Regarding the intake of supplements, the rates of subjects who answered "I take supplements" and "I spend more than 5,000 yen a month" were significantly higher $(\mathrm{P}<0.05$ and $\mathrm{P}$ $<0.001$, respectively) in subjects with liver disease compared with those without liver disease. Regarding the drinking habits of alcoholic beverages, the rate of subjects who answered "I do not drink at all" was significantly higher in the those with liver disease $(\mathrm{P}<0.05)$. Similarly, for the coffee drinking habit, the rate of subjects who answered "I hardly drink coffee" was significantly higher among subjects with liver disease $(\mathrm{P}<0.001)$. For subjects who answered "I mainly drink instant coffee", the rate was significantly higher among those without liver disease $(\mathrm{P}<0.05)$. There was no difference in the rate of subjects who answered "I mainly drink drip coffee" between those with and without liver disease. For dental clinic visits, the rate of subjects who answered "I did not visit dental clinic within 1 year" was significantly higher in subjects without liver disease $(\mathrm{P}<0.05)$.

\section{Discussion}

We previously reported on the awareness and behavioral effects of education about medical information through regional education seminars over the past 10 years. It was demonstrated that participation in the seminar more than 5 times resulted in not only improvement of knowledge on disease, but also in positive behaviors [4].

In this questionnaire survey, we examined differences in lifestyle mainly due to the presence or absence of liver disease. Results showed that the rate of subjects who participated in the Seminars for Digestive Disease more than once was high, and for most of the healthy lifestyle habits, the rates were higher in subjects with liver disease than those without liver disease. These findings suggested that subjects with liver disease earnestly participated in the regional education seminar and were also striving to maintain a regular and healthy daily life. Furthermore, based on detailed answers from the questionnaire, it was observed that many respondents took the BCAA zinccontaining nutritional supplement, Aminofeel, developed by our group. It was presumed that the content of lectures presented at the past Seminars for Digestive Disease influenced the behavioral changes of liver disease patients and their families.

The significance of administration of BCAA for liver disease is its effect on protein malnutrition and hepatic encephalopathy. The metabolic pathway of BCAA was clarified in the 1950s, and in 1976 Fischer et al. [17] clinically applied it to hepatic encephalopathy. Later, Muto et al. [18] reported that the plasma BCAA level and Fischer ratio (ratio of blood BCAA to aromatic amino acids (AAA)) had a direct correlation with the serum albumin level. Furthermore, the plasma BCAA level and Fischer ratio were improved and administration of BCAA to cirrhotic patients improved protein malnutrition by increasing serum albumin, transthyretin and transferring levels [19].

Aminofeel was developed to contain trace elements such as zinc, chromium and selenium, in addition to BCAA, in order to supplement nutrients lacking in patients with liver disease. Zinc deficiency causes various disease states, such as taste disorder. Low blood zinc levels are often observed in patients with chronic liver disease and it is thought that this is caused by several factors including an increase in zinc excretion and a decrease in zinc absorption capacity. To date, we have reported that patients with type $\mathrm{C}$ chronic liver disease indicated taste disturbance even if they were not aware of abnormal taste and decreased blood zinc level, and that the sensitivity of taste sensation was significantly improved and the blood zinc level was significantly elevated after intake of Aminofeel [8].

In order to prevent progression from chronic hepatitis to liver cirrhosis or HCC, it is important to exercise moderately to prevent reduction of muscle mass, and to consume balanced and low-fat diet, with consideration of BCAA in take. The importance of these behaviors should continue to be stressed at the regional education seminar.

On the other hand, a research group at the National Cancer Research Center found that the risk of HCC tended to decrease for subjects with high coffee intake, and similar results were obtained for HCV-infected persons [20]. Additionally, researchers found that drip coffee had an effect on liver function improvement (ALT stabilization) in patients with chronic hepatitis C [21]. In recent years, results of a survey of 2,424 Dutch people over 45 years of age without liver disease (Rotterdam study) demonstrated that intake of coffee and herb tea lowered the risk of liver fibrosis [22].

We previously discussed the fact that caffeine in drip coffee suppresses liver inflammation, as demonstrated in the 13th Seminars for Digestive Disease conducted in 2009, and we have recommended that subjects consume daily 1 to 3 cups of coffee made from ground beans. However, as a result of this questionnaire survey, few people drank drip coffee, so it seemed that further educational activities were necessary.

It is well known that periodontal disease is associated with systemic diseases such as cardiovascular diseases and type 2 diabetes. Nagao et al. [23] analyzed the pathological conditions of periodontal disease and liver disease in 351 people infected by hepatitis virus, and reported that risk factors for periodontal disease included a platelet number of less than $80,000 / \mu \mathrm{l}$, tooth brushing once/day, interferon treatment, age of over 65 years, and obesity (odds ratios were 5.80, 3.46, 2.87, 2.50, and 2.33, respectively). It has been demonstrated that periodontal disease may be involved in the progression of viral liver diseases [23]. In this research study, it was considered that people with liver 
disease had shorter intervals for dental clinic visits because they were repeatedly educated about relationships between periodontal disease and liver disease in the past Seminars for Digestive Disease.

\section{Conclusion}

Behavioral changes, such as improvement of dietary habits that patients themselves consciously struggle with, and also treatment for and prevention of progression of liver disease were recognized by continuous implementation of the Seminars for Digestive Disease for patients with gastrointestinal disease, especially liver diseases. Therefore, we believe that the value of the Seminars for Digestive Disease in our department has been demonstrated, and that appropriate and continuous implementation of these measures can lead to reduction of medical expenses through improvement of nutritional status and QOL and also prevention of deterioration of medical conditions. However, there were items for which sufficient educational activities have yet to be implemented, and there were many subjects participating for their first time. Therefore, in future regional education seminars, along with a variety of medical information it should be required to provide information on "food and nutrition", which is most important and familiar to humans. Furthermore, we will continue to analyze the survey data, and will also conduct longitudinal studies.

\section{Acknowledgment}

We thank Dr. Kazumi Yamasaki (National Hospital Organization Nagasaki Medical Center) for lectures at the seminar.

\section{Conflict of Interest}

KK-S, YK and YN belong to a department funded by Nishinihon Hospital. The remaining author disclose no conflicts.

\section{References}

1. Kuwahata M (2011) Base of nutritional therapy: Why is the nutritional therapy necessary for liver disease? (in Japanese). Kan Tan Sui 63(3): 361-366.

2. Takaki A, Iwamuro M, Matsushita H, Yamamoto K (2015) Hepatic cirrhosis: Advances in research and clinical practice (in Japanese). Annual Review Gastroenterology, pp. 99-105.

3. Shiraki M, Hanai T, Moriwaki H (2015) Nutritional therapy and exercise therapy for viral chronic hepatitis/liver cirrhosis. Medicina 52(2): 350352.

4. Nagao Y, Kawahigashi Y, Sata M, Nobayashi H (2015) Effect of patient education seminars on awareness and behavior of individuals with viral liver disease. Med Sci Tech 56: 120-126.

5. Nagao Y, Kawahigashi Y, Kimura K, Nobayashi H, Sata M (2017) Awareness survey of prejudice and discrimination in hepatitis $B$ and C virus-infected individuals. Adv Res Gastroentero Hepatol 7(1): 1-6.

6. Kawaguchi T, Taniguchi E, Itou M, Sumie S, Oriishi T, et al. (2007) Branched-chain amino acids improve insulin resistance in patients with hepatitis $\mathrm{C}$ virus-related liver disease: report of two cases. Liver Int 27(9): 1287-1292.
7. Kawaguchi T, Nagao Y, Matsuoka H, Ide T, Sata M (2008) Branched-chain amino acid-enriched supplementation improves insulin resistance in patients with chronic liver disease. Int J Mol Med 22(1): 105-112.

8. Nagao Y, Matsuoka H, Kawaguchi T, Sata M (2010) Aminofeel ${ }^{\circledR}$ improves the sensitivity to taste in patients with HCV-infected liver disease. Med Sci Monit 16(4): 7-12.

9. Nagao Y, Kawaguchi T, Kakuma T, Ide T, Sata M (2011) Post-marketing surveillance study for efficacy and safety of Aminofeel ${ }^{\circledR}$, a branched chain amino acids-enriched supplement including zinc (in Japanese). J New Rem \& Clin 60(5): 1046-1063.

10. Nagao Y, Kawaguchi T, Ide T, Sata (2012) Effect of branched-chain amino acid-enriched nutritional supplementation on interferon therapy in Japanese patients with chronic hepatitis C virus infection: a retrospective study. Virol J 9(282): 348-356.

11. Kawaguchi T, Nagao Y, Abe K, Imazeki F, Honda K, et al. (2015) Effects of branched-chain amino acids and zinc-enriched nutrient on prognosticators in HCV-infected patients: A multicenter randomized control trial. Mol Med Rep 11(3): 2159-2166.

12. Nagao Y, Sata M (2013) Effect of a late evening snack of amazake in patients with liver cirrhosis: a pilot study. J Nutr Food Sci 3(5): 223228.

13. Toyonaga A, Okamatsu H, Sasaki K, Kimura H, Saito T, et al. (2000) Epidemiological study on food intake and Helicobacter pylori infection. Kurume Med J 47(1): 25-30.

14. The Japan Society of Hepatology (2016) Chronic hepatitis C: Guide for diagnosis of chronic hepatitis and liver cirrhosis (in Japanese), pp. 2355.

15. Enomoto N, Takehara T, Mochida S (2014) Basics-Basic knowledge before examining hepatitis C. Hepatology Practice Volume 3; Mastering the clinic of hepatitis C (in Japanese), pp. 23-31.

16. Kudo M, Izumi N, Ichida T, Ku Y, Kokudo N, et al. (2016) Primary liver cancer follow-up report 2006 2007 Japan Hepatic Cancer Study Follow-up Survey Committee (in Japanese). Kanzo 57(1): 45-73.

17. Fischer JE, Rosen HM, Ebeid AM, James JH, Keane JM, et al. (1976) The effect of normalization of plasma amino acids on hepatic encephalopathy in man. Surgery 80(1): 77-91.

18. Muto Y, Yoshida T, Yamafuji M (1983) Nutritional treatment of chronic hepatic insufficiency-On branching chain amino acid replacement therapy (in Japanese). Japan Medical Journal 3101: 3-8.

19. Kawade Y, Yoshida T, MoriwakiH, Hayashi M, Sakata Y, et al. (1979) Decompensate cirrhosis and amino acid nutrition - Effects of branched chain amino acid administration on plasma prote in concentration and urinary excretion of 3-methylhistidine (in Japanese). Kanzo 20(6): 625.

20. Inoue M, Kurahashi N, Iwasaki M, Shimazu T, Tanaka Y, et al. (2009) Effect of coffee and green tea consumption on the risk of liver cancer: cohort analysis by hepatitis virus infection status. Cancer Epidemiol Biomarkers Prev 18(6): 1746-1753.

21. Sasaki Y, Ohfuji S, Fukushima W, Tamori A, Enomoto M, et al. (2013) Effect of caffeine-containing beverage consumption on serum alanine aminotransferase levels in patients with chronic hepatitis $C$ virus infection: a hospital-based cohort study. PLoS One 8(12): 1-9.

22. Alferink LJM, Fittipaldi J, Kiefte-de Jong JC, Taimr P, Hansen BE, et al. (2017) Coffee and herbal tea consumption is associated with lower liver stiffness in the general population: The Rotterdam study. J Hepatol 67(2): 339-348.

23. Nagao Y, Kawahigashi Y, Sata M (2014) Association of periodontal diseases and liver fibrosis in patients with HCV and/or HBV infection. Hepat Mon 14: e23264. 
Your next submission with JuniperPublishers will reach you the below assets

- Quality Editorial service

- Swift Peer Review

- Reprints availability

- E-prints Service

- Manuscript Podcast for convenient understanding

- Global attainment for your research

- Manuscript accessibility in different formats ( Pdf, E-pub, Full Text, audio)

- Unceasing customer service

Track the below URL for one-step submission https://juniperpublishers.com/online-submission.php 